\title{
Additional Labors of the Entrepreneurial Self
}

\author{
*SEYRAM AVLE, University of Massachusetts Amherst, USA \\ *JULIE HUI, University of Michigan, USA \\ SILVIA LINDTNER, University of Michigan, USA \\ TAWANNA DILLAHUNT, University of Michigan, USA
}

\begin{abstract}
Workers are increasingly expected to take on the responsibility and effort of preparing for employment in the new economy, where digital technologies play a central role in bridging access to resources, connections, and opportunity. Drawing from multi-year studies of entrepreneurs in Accra and Detroit, two cities that continue to experience high rates of inequality and persistently low incomes for the majority of their residents, this article highlights three key challenges to self-entrepreneurialization in the digital age: self-upgrading, maintaining technology, and overcoming exclusion. Locating these challenges at the intersection of (1) two powerful global discourses of entrepreneurialism and technology upgrade and (2) class frictions and racial dynamics, this paper uncovers ways in which CSCW might support entrepreneurialism in the new economy, particularly given that it is becoming a de facto space of work and mode of living. ${ }^{1}$
\end{abstract}

CCS Concepts: • Human-centered computing $\rightarrow$ Ethnographic studies; Empirical studies in collaborative and social computing.

Additional Key Words and Phrases: entrepreneurship, low-income communities, digital skills, new economy

ACM Reference Format:

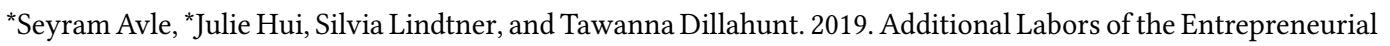
Self. Proc. ACM Hum.-Comput. Interact. 3, CSCW, Article 218 (November 2019), 24 pages. https://doi.org/10. $1145 / 3359320$

\section{INTRODUCTION}

In April 2016, Kofi was working as a network administrator and an entrepreneur in Accra when he decided to attend a coding and entrepreneurship bootcamp organized by a local tech hub. ${ }^{2}$ When asked why, on top of the multiple gigs he held and the heavy traffic he had to endure daily to get to the class, he told the first author that he felt the need to "upgrade [his] knowledge." Learning mobile app development for Kofi was a way to simultaneously build an app to solve a longstanding problem of locating cooking gas (sold in portable cylinders) in his local community and add to his growing set of self-taught digital skills.

The belief that digital technologies provide new opportunities that can lead to socio-economic mobility is pervasive [27, 29, 82]. Similarly, entrepreneurship is seen as a path to economic mobility

\footnotetext{
${ }^{1 *}$ S. Avle and J. Hui contributed equally to this work.

${ }^{2}$ We use pseudonyms throughout this paper.
}

Authors' addresses: *Seyram Avle, University of Massachusetts Amherst, Department of Communication, 650 N Pleasant St, Amherst, MA, 01003, USA; *Julie Hui, University of Michigan, School of Information, 105 S. State Street, Ann Arbor, MI, 48105, USA; Silvia Lindtner, University of Michigan, School of Information, 105 S. State Street, Ann Arbor, MI, 48105, USA; Tawanna Dillahunt, University of Michigan, School of Information, 105 S. State Street, Ann Arbor, MI, 48105, USA.

Permission to make digital or hard copies of all or part of this work for personal or classroom use is granted without fee provided that copies are not made or distributed for profit or commercial advantage and that copies bear this notice and the full citation on the first page. Copyrights for components of this work owned by others than the author(s) must be honored. Abstracting with credit is permitted. To copy otherwise, or republish, to post on servers or to redistribute to lists, requires prior specific permission and/or a fee. Request permissions from permissions@acm.org.

(C) 2019 Copyright held by the owner/author(s). Publication rights licensed to ACM.

2573-0142/2019/11-ART218 \$15.00

https://doi.org/10.1145/3359320

Proc. ACM Hum.-Comput. Interact., Vol. 3, No. CSCW, Article 218. Publication date: November 2019. 
for those in low-resource environments [61]. When the two come together, they form a powerful neoliberal discourse that finds currency around the world. Prior work from CSCW and adjacent fields such as HCI and Communication Studies have shown that in regions as varied as Africa, Asia, the Caribbean, Latin America, and the Middle East, the expectation that citizens become entrepreneurial and technologically savvy is inextricably entangled with city, regional, and national aspirations of socio-economic progress, even when there is little infrastructural support $[12,13,19,21,62,63,74-$ 76]. This body of work shows that often, digital technologies (e.g., apps, IoT, etc.) and digital skills (e.g., coding, making, etc.) are positioned by advocates of entrepreneurship as necessary accompaniments for individuals, cities, and nations to succeed. The entrepreneurial self in the new economy is, in many ways, a project of self-improvement and self-reliance, one that rests on citizens and workers taking up new digital skills and technologies in order to catch up, upgrade, or innovate $[10,79,91] .^{3}$

To understand the global impact of these digital entrepreneurial expectations on low-income populations that have less access to digital technologies, we examined experiences in two cities (Accra and Detroit) commonly highlighted for their efforts to overcome socio-economic instability. Accra and other African cities, such as Nairobi and Lagos, in recent years have been characterized by some sections of Silicon Valley as new sites of technological innovation [12]. Similarly, Detroit and the surrounding Midwest region has been characterized as a possible site for the rejuvenation of the former Rust Belt $[7,18,25]$. In such narratives, both digital technologies and entrepreneurship are central to the imagined possibilities for the future of these cities and their inhabitants. As the narrative goes, investing in technology and entrepreneurship will help reduce unemployment, create opportunities, and make lives better for those living in these cities. As a result, both cities have seen an increase in programs and organizations such as tech hubs and business incubators to support residents to become digitally skilled entrepreneurs $[1,3]$.

As we will show, becoming an entrepreneur (digital or otherwise) is not a straightforward process. The labor associated with the entrepreneurial process is additional to day-to-day responsibilities, and often risky when one must continue to earn a living. Arguably, life in low-income cities is already entrepreneurial. That is, a significant proportion of the population holds part-time jobs, is self-employed, and works in the informal sector [5,38]. Most of the participants in the research we drew on for this paper had multiple jobs/gigs/side hustles to earn enough income to live on. Entrepreneurship has long been used to create self-employment [61] and "hustling" is a way to socially and economically navigate precarious urban environments, a necessity that is increasingly prevalent in both the Global North and Global South $[15,69,104,113]$. Our findings describe the labor that must be done on the side to acquire digital and business skills, be it managing a social media account for business, or driving hours to learn how to code or run a startup. It may be all but invisible to those not doing it but nevertheless is a key structure of contemporary living in the new economy for low-income communities.

More specifically, in this paper, we show: (1) In response to the increasing pressure from the dual discourse of entrepreneurship and digital technology, entrepreneurs in Accra and Detroit exhibit efforts to upgrade the self in a future-oriented outlook toward learning how to perform entrepreneurship and use related technologies for creating career opportunities, all while maintaining a precarious livelihood. (2) There is the need for technology maintenance, i.e. using (often) older-generation digital technologies that low-resource workers tend to have, to join the digital economy. The cost of constantly upgrading to new technologies is too high relative to income,

\footnotetext{
${ }^{3}$ We define the "new economy" as the period beginning in the 1990's during which employment began to be shaped by new, and often riskier, job opportunities as a result of the dot-com boom, death of manufacturing plants, and changes in institutional arrangements $[26,84]$.
} 
and so entrepreneurs in both cities often seek help to repair devices or to learn how to use them with newer systems or programs. (3) Tied to the specific socio-political issues of their localities, entrepreneurs in the two cities have to consistently labor toward overcoming exclusion. In Detroit, this comes from the city's racial history, as well as its identity as a former industrial powerhouse within the USA. In Accra, it is Ghana's colonial history, the mechanics of its post-independence governance, and its place in the global imaginary as an African country that structured some of the exclusions entrepreneurs experienced.

On their own, each of these findings confirmed what prior research has shown about the technological and economic needs of low-income populations, particularly in research from related fields such as ICTD. However, together, we argue that they form a potent mode of precarious urban living that is tied to entrepreneurship as a de facto mode of work for increasing numbers of people in a world with growing dependence on digital technologies. More specifically, this paper contributes to CSCW by locating the pressure that people living in low-income areas feel at the intersection of two powerful discourses about changing work practices in the new economy: entrepreneurialism and digital technology skills. As we will show, Accra and Detroit dwellers who were already entrepreneurs were actively acquiring digital tech skills in an effort to enhance their ability to earn a living and be upwardly mobile. Others who had already started acquiring technical skills reported an urgent need to learn how to become better entrepreneurs. Together, participants felt a strong impetus to combine the acquisition of various technical skills - ranging from social media promotion, coding, making, etc. - with the task of learning to become an entrepreneur, while juggling multiple gigs or hustles on the side. The digital is bound with class and aspirations of upward mobility for the self and community just as much as it is a means to maintain livelihood.

Further, the findings about how Accra and Detroit residents navigate and overcome exclusions underline an important but unaddressed aspect of social dynamics within CSCW: the intersection of class and race within the entrepreneurial space. While class mobility and solidarity have been identified as crucial to supporting various labor conditions, much prior work focused on and within specific classes, e.g. [31, 105]. However, what we show is that the cultural frictions between different but geographically proximate social classes intersect with race and manifest as exclusions on both local and transnational levels. Within the new economy, entrepreneurs need to regularly interface and interact with networks outside their class, especially if they wish to be upwardly mobile. By showing how class frictions occur in cities in two different regions, we unpack how social class intersects with race in a globalized labor economy that requires individuals to become entrepreneurs and upgrade themselves through digital technology skills.

\section{RELATED WORK}

To understand the additional labors of the entrepreneurial self, we draw from recent work on entrepreneurship in CSCW literature and frame these activities within corresponding conversations on digital and offline labor in the new economy.

\subsection{Risk and Aspiration in the New Economy}

The literature on labor in the new economy is vast and largely focuses on people's effort to advance, or even just maintain, their socio-economic standing. We drew on research that has articulated specific forms of labor that are increasingly common in the new economy. For instance, venture labor describes how workers are choosing jobs that allow for greater autonomy and creativity, but also require more risks typically absorbed by traditional organizations [84]. For instance, someone who quits a stable job in IT to take a position in a startup with lower pay and fewer health care benefits for a "chance to make millions" is undertaking venture labor. Similarly, and more commonly, someone moving from being an employee of a firm to being an Uber driver is undertaking venture 
labor. This kind of labor movement works to normalize risk within careers associated with the new economy, which, combined with the instability of gig work, has given rise to what Amrute called "the neoliberal colonization of life by work"[p. 2][9].

This notion of the colonization of life by work points to the "constantly on" nature of gig work in the new economy. Work life now routinely extends beyond the 9-to-5/40-hour work week in ways that are tied to the increased need for workers to become entrepreneurial to survive the changing labor market. Moreover, it is not uncommon for this kind of venture labor to also take on emotional labor as part of the job. Emotional labor describes the management of one's emotions to produce a positive effect in others (usually customers) within service jobs [109]. Within CSCW and related fields, work has shown that Uber drivers constantly perform emotional labor to get the high ratings that are central to their wages [94, 96]. Similarly, Nemar et al. [85] demonstrated how Airbnb hosts extend their work day as they perform emotional labor to accommodate guests in their homes. Much of this previous work focused on contexts where workers serve customers and are within a formally defined relationship, usually employment, even if it is part-time.

In contrast, entrepreneurship requires creating one's own employment opportunities, a process that involves setting day-to-day responsibilities, acquiring resources, and determining short- and long-term plans. People who do freelance work are living entrepreneurial lives as they work toward acquiring gigs, keeping clients, and advancing into new areas of business. The existing research on such ventures within CSCW and related fields has examined online work [23], bias and wage differences [53,102, 103], and how workers navigate being nomads and creatives [73], among other issues. How entrepreneurialism functions offline within the context of the new economy has not been addressed by CSCW, a gap this paper helps to fill.

Outside of traditional 9-to-5 work, other research has described the work performed and risks taken to gain more meaningful employment as aspirational. Brooke Erin Duffy [33] described the concept of aspirational labor as the effort people choose to invest toward acquiring employment in their dream job, such as purchasing luxury products to become an influencer on social media The labor expended may be under-compensated or not compensated at all in the present, but the hope is that later it will pay off through different forms of remuneration and future employment opportunities [70]. These studies have typically described this form of labor with respect to models or social media influencers, who might for instance purchase expensive clothing and edit hours of video documenting their day-to-day life in hopes of becoming "discovered." On the other hand, followers might also engage with these influencers in the hopes of being noticed or made visible and thereby rewarded for their engagement [6].

While not suggesting that those described by venture and aspirational labor are immune to hardships, we found that the literature largely focuses on middle-class populations who can afford to bear the risks by relying on their savings, families, education, class, etc. What we detail in this paper are situations that are far more economically precarious, where the option to stop working for a full- or part-time job can be disastrous to one's daily livelihood and aspiration toward upward mobility. We describe the additional effort entrepreneurs in resource-constrained communities put forth to keep up with technology-heavy expectations of the new economy. Further, whereas these earlier studies have largely focused on online efforts, we detail a space in which a combination of online and offline work is taken up in anticipation of socio-economic advancement alongside the continued task of earning a living.

\subsection{Living the Hustle Life: From Gig Work to Entrepreneurialism}

While some HCI research depicts the hustle of entrepreneurialism as inevitable and even desirable [69], others within CSCW have shown not only how this discourse is made and unmade through neoliberal governance, but also how people seek alternatives even as they co-produce the very logics

Proc. ACM Hum.-Comput. Interact., Vol. 3, No. CSCW, Article 218. Publication date: November 2019. 
that entrench entrepreneurial living as a fixture of global capitalism [13, 61, 63, 75]. In general, we perceive a recognition within CSCW that new work contexts tied to entrepreneurial modes of living are emerging beyond the typical 9-to-5/40-hour weeks. Recent research on the gig and sharing economies indicates growing efforts to better understand and support work as it unfolds within people's entrepreneurial ventures and side hustles. Some studies have examined how technological systems mediate and order the experiences of these individuals, highlighting algorithmic bias and black-boxing as central challenges for creating a fair and safe working environment for the millions engaging in gig work to earn a living wage. In response, gig workers, many of whom are making minimum wage or below [90], must invest additional effort to self-organize and share information that helps them understand gig economy procedures and algorithms [46, 72]. For instance, Gray et al. $[50,51]$ described how crowd workers connect with each other offline and online to learn rules on platforms like Amazon Mechanical Turk.

As gig work and entrepreneurialism becomes normalized in both the Global North and Global South, we argue for the process of becoming an entrepreneur (or self-entrepreneurialism) to be studied as an important work space within the purview of CSCW research. In the USA alone, about 40 million people reportedly have a side hustle, although that money earned is not extra but in fact going toward making ends meet [15]. Younger people are more likely to have or need a side hustle, in part because of shifting labor conditions associated with corporate employment and the diminishing likelihood that there will be the kind of long-term stable employment their parents relied on for class mobility and socio-economic security $[15,26,71]$. These job and employment uncertainties have risen with unstable economic conditions, from austerity measures to large-scale failures of financial markets in North America, Europe, Latin America, and Asia.

Elsewhere, the link between youth and hustling is described as a feature of urban living, marginality, and the desire for upward mobility. For instance, tech entrepreneurs in Accra and Kingston understand the work they do to be part of a general hustle toward a better life [13]. For young Kenyans, from educated middle-class workers to slum residents, the hustle takes place both online and offline [83, 112]. Thieme [104] located various practices of hustling within precarious urban geographies and theorized what she called "the hustle economy" as a "localized but globally resonant condition of contemporary urbanism, coupling generative possibilities that emerge from everyday experiences of uncertainty and management of insecurities associated with 'life work' outside the bounds of normative social institutions" (p529). Hustling, by this token, is a contemporary condition of making a living through uncertainties and connects the experiences of "precarious labor markets in rapidly urbanising cities of the global south back to industrialised (or post industrial) cities of the global north" [ibid].

A key goal of this paper is to underscore this globality. We do this by connecting the experiences of people living in the Global North and the Global South. Indeed, the more recent increase in and normalization of self-entrepreneurialism through gig and side work in the Global North demonstrate conditions that look quite similar to what has long been theorized as characteristic of life in the Global South. This suggests that these developments are better understood more broadly as key problems of our time rather than characteristic of specific places [24]. This generates an impetus for looking more closely at how these work contexts and modes of living are unfolding in tandem across geographic regions that hitherto might have been separated by their levels of industrialization.

CSCW's definition of "work" has always been in flux as computing and social conditions change $[80,97]$, and we perceive an ecosystem in which CSCW research might be supportive and applicable for people living entrepreneurial lives in low-income areas. The conflicting perception of how entrepreneurial work ought to impact the lives of the economically vulnerable versus how it actually does often leads to technology designs that are unintentionally inappropriate or discriminatory $[29,103,110]$. Prior work has shown that digital platforms that are often presented as accessible 
to all are only beneficial to the extent of the user's network and other socio-economic factors $[45,60]$. For example, crowdfunding platforms are supposed to hack traditional barriers to financial capital by leveraging the power of the crowd, but in many ways they still mimic offline inequalities $[58,60,81]$. For workers in parts of the Global South, some of these so-called global platforms are not even available, exacerbating their relative disadvantages [13]. For low-income workers in more affluent economies, being on the lower end of the digital divide sets up additional challenges $[27,28]$ in which even the most well-intentioned assistance brings more burdens to overcome. What this paper contributes to this body of work is in identifying the intersection of a global discourse of technology uptake and entrepreneurialism as a key source of pressure for low-income workers in urban spaces like Accra and Detroit. Furthermore, this research unpacks how another intersection, this time between social class and race, manifests as challenges for such populations.

\section{METHODS}

This paper draws on ethnographic work from two cities, each focused on understanding the role of digital technologies in both the everyday and professional lives of entrepreneurs in resourceconstrained contexts. We brought the two sites together to highlight the ways that these two populations are similar and share experiences of trying to live an entrepreneurial life in the new economy under precarious labor markets and changing urban conditions. While Accra and Detroit differ in a number of ways with respect to geography, racial demographics, and culture, we found similarities that challenge the common perception that only the Global South is poor and the Global North wealthy, particularly in terms of technology access and use. This view persists despite recent $\mathrm{HCI}$ and HCI4D research showing unrelenting inequalities and a digital divide across some urban and rural Global North populations [27, 29, 54]. Following these and other prior works that advocate for alternate lenses in viewing socio-technical practices around the world $[64,89,111]$, we position this paper as a study of entrepreneurial work and life within resource-constrained communities in globally connected cities. We took each of these sites as case studies of self-entrepreneurialism in a first level of analysis, whereby we compared and contrasted the ways participants in the two cities tried to carve a path toward acquiring digital skills and learning to become entrepreneurs.

Case studies have a long history across disciplines and "emphasize the rich, real-world context in which the phenomena occur" [p. 25][37]. The goal of such research is to generate deep insights that might facilitate theory-building and nuanced understanding of socio-cultural phenomena. To uncover deeper insights that might serve as the basis for theory building, cases undergo additional levels of analysis in which researchers discuss findings from the case studies together, cycling through findings in an iterative manner. This gleans from each case discrete examples, contrasts, and extensions upon which the emerging theory rests [37, 99, 114]. While this additional analysis presents broader insights that might be applicable across contexts, the goals of the ethnographic work underpinning this type of research are not the generalizability or replicability that quantitative research aims for. Rather, case studies uncover systemic socio-cultural issues that require rich context to understand and subsequently theorize. This has worked well in CSCW research where essential theories such as postcolonial computing [64], repair values [57], and others [66] have emerged. We followed this method in this paper, informed by a shared understanding of the global dynamics shaping the discourses of digital technology and entrepreneurship. This is important because a key contribution of this paper lies in its cross-regional scope, providing a framework for the theorizing of entrepreneurial labor within CSCW.

In the second level of our analysis, we identified cross-cutting themes and sub-codes. Where there was disagreement about the applicability of a particular theme in one of the sites, the researchers from that site provided additional data that might support or dispel the validity of that theme. This was then again discussed until there was agreement on whether the theme was applicable across

Proc. ACM Hum.-Comput. Interact., Vol. 3, No. CSCW, Article 218. Publication date: November 2019. 
sites and whether it generated new insight into the labor of entrepreneurship in low-income cities. Following that iterative cycle of coding and discussion, we determined three higher-level themes (our main findings), some of which had corresponding sub-themes that we detail later.

In the process of uncovering these themes, we privileged the lived experiences, perceptions, and strategies of people in these cities in which digital technologies and entrepreneurialism are positioned in the public discourse as essential tools for socio-economic growth. In our analysis, we took a cue from the study of capitalism in cultural geography and anthropology $[86,87,107,108]$ to situate the lives that our study participants shared within a complex network of global capitalism and localized socio-politics. Embedding what we observed in the histories of the two cities was crucial to understanding how the shared burden of self-entrepreneurialism unfolds in these localities. Taking such an approach allowed us to emphasize how urban living conditions within this globally connected world evince a need for more nuanced understanding of discourses of technological progress and their impact on lived experience in low-resource communities around the world. The labor precariousness in both cities marks the discourse of technology-enabled entrepreneurship as particularly potent, and a crucial site for intervention to support improved standards of living. An important aspect of the research that we draw on here involves a discourse analysis of technology and entrepreneurship in the various sites; this includes being attendant to public discourse as seen through various media platforms, government action, and the narratives that circulate in and outside the country about using/producing digital technologies alongside entrepreneurship. Next, we provide background details of the studies from which each of the cases was derived before moving on to our findings.

\subsection{Accra Study}

In Ghana, the population in the original study might be considered middle class when compared to others in the country. Yet, as a low-income country, wages for formal work in Ghana tend to be low, and self-employment is a common recourse to cover the shortfall [5]. ${ }^{4}$ As the capital city of Ghana, Accra holds most government institutions, necessitating a heavy inflow of citizens seeking administrative support of all kinds. Recent efforts to decentralize public administration have not de-congested the city, in part because the decentralizing efforts have not been tackled at the governance level. Furthermore, the city's largely unplanned infrastructure, an area of 87 square miles for a population 2.25 million, makes Accra a densely populated space, one that struggles to accommodate a steady stream of migrants from all over the country. This, coupled with persistent low wages and lack of formal employment for the largely youthful population, makes life in Accra, by many standards, a challenging one for almost all but the elite/wealthy. Accra's average income is higher than the rest of Ghana, but the city also hosts some of the nation's most destitute, particularly those who migrated from rural parts of the country in search of work and now live in slums dotting the city's landscape [5]. Still, Accra is often depicted as an emerging site for innovation, with Ghana's political stability and macroeconomic growth lauded as a shining example in Africa [2,12].

The case from Accra drew from the last 2.5 years of a long-term ethnographic study of tech entrepreneurship and its evolution as a mode of work in Ghana, on a continent perceived to be on the periphery of global technological innovation. The overall project took an ethnographic approach toward documenting, analyzing, and theorizing how new modes of work have emerged within the new economy, taking into consideration infrastructural gaps and the lived experiences of those undertaking that work.

\footnotetext{
${ }^{4}$ Mean annual household income is about GHC 16, 600, the equivalent of USD 3000. Of this, the Ghana Living Standards Survey round 6 (2014) shows that non-farm self-employment contributes 48.3 percent to household incomes with wages from employment the second major contributor, followed by household agriculture.
} 
Within the subset of data from the last 2.5 years are individuals who are entrepreneurs part time and have been trying to upgrade themselves through the acquisition of digital technologies and skills. The findings discussed in this paper are from semi-structured interviews (average 45 minutes to 1 hour each, $\mathrm{n}=84$ ) that took place at various sites and events around the city. The ages of the interviewees ranged from early 20 s to the early 50 s, and 29 of those interviews were with women. All participants are Ghanaians and have lived in either Accra or the next largest city, Kumasi, for most of their adult lives.

The events attended included hackathons, bootcamps, workshops, barcamps, and conferences, and the locations varied from hubs where most startups operate out of, to hotels, trade fair venues, government ministries, and public parks. When not at these events, we were participant observers in two hubs in Accra. Tech and business hubs function as the primary site for the training and support of entrepreneurs and technologists and about 64 percent of Ghana's tech hubs are based in Accra. ${ }^{5}$ It is here that those "in the know", such as Kofi from the introduction of this paper, get their support and training.

\subsection{Detroit Study}

The U.S. study population is from Detroit, a city undergoing profound economic changes as it attempts to recover from not only the 2008 financial crisis, but also the relocation of manufacturing jobs outside the city over the last decades. Largely African-American, this Detroit study population operates in a social and economically segregated environment. Over the last 60 years, Detroit has gone from the 4th largest to 23rd largest city in the United States, reflecting a declining population over time. The auto industry that placed it as the industrial powerhouse of the world began to move outside the city in the 1950s, causing a sharp economic decline as the majority of businesses closed or moved away. Because of longstanding housing segregation, the majority of the White/Caucasian population followed the jobs to the suburbs, leaving behind a hollowed out economy and a largely African-American population [100].

Today, reports and popular press express that Detroit is experiencing a comeback [7, 18, 25] and laud entrepreneurship as a community-based approach to city growth. At the time of writing, there were more than 54 entrepreneurship support organizations, with many grassroots endeavors to build networks and community among business owners and startups in the city [1]. However, for many, this story of revitalization is a tale of two cities $[8,95]$. While the downtown/midtown area are experiencing a boom in economic economy, bordering neighborhoods are still living in poverty. For example, certain areas of downtown Detroit report a median household income around USD 50,000, whereas some surrounding neighborhoods report median incomes as low as USD 9,000. In effect, a disproportionate growth in the city center has created an imbalance in who receives entrepreneurial support and resources.

The findings from Detroit drew from two related studies of entrepreneurs, also from the last 2.5 years. One study involved interviews with 26 low-resource entrepreneurs (18 female) from the greater Detroit metropolitan areas. Eighteen identified as Black/African American, five as White/Caucasian, one as Hispanic/Latino/Latina, one as Middle Eastern/North African, and one as Asian/Asian American. These demographics closely represent the racial composition of Detroit per the most recent available U.S. Census data in 2010 (82.7\% Black/African American, 10.6\% White, 3\% other races and $1.1 \%$ Asian) [4]. The other study followed a participatory action research approach that involved working with 17 entrepreneurs and a local organization on Detroit's Eastside (13

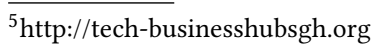


female), where the median household income was USD 25,000. All participants identified as AfricanAmerican. The majority of participants from both studies lived in the greater Detroit area for more than 15 years.

Like the study of Accra, the goal here was to understand the work of performing entrepreneurship in resource-constrained contexts, and the role technology played in this process. The findings here drew from observations and semi-structured interviews ranging from 30 minutes to an hour, based on core questions addressing participants' prior and ongoing engagements with digital technology for work and professional advancement. Observations and participatory action research took place across non-profit organizations, incubators, co-working spaces, and marketplaces.

\section{FINDINGS}

The three main findings about the additional labor that entrepreneurs in Accra and Detroit have to undertake to self-entrepreneurialism in the new economy are self-upgrading, technology maintenance, and overcoming exclusion. We denote findings for Accra and Detroit by [A] and [D], respectively, at the beginning of each paragraph where we unpack each finding.

\subsection{Upgrading the Self}

We found that becoming an entrepreneur with the necessary set of skills and technologies, at its core, was about being proactive toward carving out a particular future for the self and community. This meant, for many of our participants, upgrading the self through self-learning, education, and practicing new skills, all done on top of maintaining a livelihood. We observed that the additional labor of upgrading the self was visible in two spheres: the digital space and the physical world. Much of this work involved getting to and from spaces in which one could learn a new skill, encounter like-minded others, navigate the urban infrastructure, and find resources online to self-teach. Crucially, participants thought of these as working to both keep up and stay ahead of the curve. The labor of upgrading then was both taking a proactive stance and adapting to shifting tides in the global economy.

4.1.1 Physical Labor of Upgrading. Low-income populations in both Accra and Detroit were most in need of technological and entrepreneurial learning opportunities, but were also located furthest from these resources. The added pressures of sometimes working multiple jobs or managing family responsibilities and traveling to these opportunities were particularly challenging.

[D] Detroit has seen a number of business- and technology-focused hubs in recent years [92]. However, the latter were primarily located in the affluent city center. Some non-profit organizations dedicated to small business development were more likely to hold events outside the city center to support entrepreneurship training among low-income groups. Despite efforts to bring some of the training to different locations in the city, participants still faced time and transportation constraints in attending events regularly.

One food entrepreneur, Anetta, described learning the online and offline requirements for her business at a weekly workshop over an hour's drive away. When asked what motivated her to start her business, she explained that she wanted to find healthy snack alternatives for children. She was a retired schoolteacher in a county where more than 50 percent of students were on free and reduced lunch plans. While she could have located to downtown Detroit, where the majority of entrepreneurship training programs are located, she emphasized that it was critical to base her business in her current neighborhood where jobs and healthy food were needed most. Instead, she made the long commute each week to attend classes. She explained: 
"I found that here in [my town] there was no resources. I mean I tried ... If you know that you have something, and also you're in an environment that cannot tell you anything about the food industry; where to start, how to package..."

While some of this knowledge could be learned through online tutorials, like MOOCS on business development, she explained how a lot of the knowledge to get started was not often discussed publicly. It was easier to obtain local industry-specific knowledge by attending classes in person, even if it was an hour away:

"They talked about interviews, business plans, there was a lot of sharing. We were exposed to lawyers, we talked about IP, intellectual property with foods ... I had to continuously drive to get that knowledge."

Anetta's experience highlights a common theme that building in-person connections with people in the industry is not easily available through online channels, yet is crucial for entrepreneurial success. Anetta's snacks are now sold in her local grocery stores, but other participants were not as lucky when it came to accessing the transportation needed to get started. Some explained missing networking events because they did not own a car, or needing to rely on friends to drive them to meetings only a few miles away that would have taken over an hour to get to by public transportation.

[A] Accra, on the other hand, has more public transportation available but the city's congestion and traffic situation make moving about tedious. This was found to be manageable on a daily basis if one had only one commute to make. However, if one had to move around the city to various locations in a day, the travel infrastructure quickly became untenable. For entrepreneurs like Kofi, who we introduced at the beginning of this paper, a good percentage of the productive day was spent traveling what is technically a short distance, cutting into the time that could be spent doing work. From his workplace, to the gigs he did for extra money, to the location of the coding school, he spent a lot of time getting around. Another entrepreneur, Kweku, who had a running startup, was very detailed in his description of how this all works on a daily basis. He said:

"I wake up in the morning, pick my heavy laptop with my modem and my heavy adapter, I pick a handkerchief because it's very sunny and sweaty, I get in a trotro, ${ }^{6}$ check the calendar on my phone and map out my route in my head. I move from Adenta to Legon or Circle because I have to do a demo [to a prospective client] who is on a very tight schedule. From there I have to move to do another demo. I am in a trotro with four people in a tight place, trying to get myself not too sweaty so that I can look professional when I get there. It's a very demanding landscape ... Sometimes I walk for long distances and I have to use Google map to try and locate where the [client] is because all that [the person] tells me is to take a left, take a right and all that ... It's a very demanding landscape, but you have to."

Kweku viewed the "demanding landscape" as part of the urban grind, necessary for even this new startup world that he was engaging in. Having graduated from one of the tech hubs, he had been exposed to the same kinds of ideas and methods taught to Silicon Valley entrepreneurs, from bootstrapping to the lean startup. He had even joined an accelerator in another African country for a few weeks. Yet, the necessity of using an informal public transportation system alongside the absence of a functioning address system in parts of Accra made the entrepreneurial aspects in Accra more strenuous, marking his software startup with extensive physical labor, not just digital.

${ }^{6} \mathrm{~A}$ Trotro is a public minivan akin to a matatu in East Africa. 
4.1.2 Digital Labor of Upgrading. Similarly, entrepreneurs who lack access to traditional knowledge networks, such as through school or work, must turn to other avenues, often at a cost, to get the information they need.

[D] In Detroit, most of our participants said they found social support for learning new skills online through groups on social media. For instance, Lana, who had a candle and soap business, described how she found a mentor on Instagram:

"I think I was looking just at some of the other people I may be interested in and I came across her. I started following her and just really reading a lot of the different information that she was posting on Instagram ... We're like our own little community. We pay a fee every month, but she shares so much and she's so motivating and encouraging. Sometimes she gives us that tough love. We have total complete access to her. She's been heaven-sent actually. She reminds us that we have to do our work."

Lana expressed that participating in this group was necessary for accessing "different tools" and "moving [her] business to a new level." Participating in online private entrepreneurship groups was relatively common among our participants; many of them expressed that it was the only way they could get the information and support needed to start a business. However, she and others expressed hesitancy with becoming engaged on social media for networking and publicity. She could connect with customers on a personal level one-on-one but faced difficulties sharing information about herself online:

"I've never been a social media person, so when I started my business I had to get on social media. Now I have to begin posting things about myself. It took me a really long time just to put my image on my website because I'm so private. That's another thing I had to overcome just sharing all that with the public."

While social media provided new ways to access social support in performing entrepreneurial work, marketing online was described as very psychologically draining. With the growth of Facebook and Instagram, many felt extra pressure to cultivate an online presence, which often added stress to their already busy schedule of running a business and making connections offline.

[A] ] Over in Accra, entrepreneurs would frequently mention going online to access learning tools to become more knowledgeable or technically skilled. Yaw, a young man who had dropped in and out of school but was known in the hardware circles as a gifted maker, spoke about how he learned most of his skills by going on YouTube, reading tutorials, and buying cheap Arduinos and other accessories from China. He explained:

"I found programming and thought, this is the ticket out of this madness. I did a lot on my own. One time I was learning how to program embedded systems, Arduinos, Raspberry Pi and things ... I was scrapping a lot of tutorials online ... but you know people can't pay the 10 dollars online so sometimes you go to YouTube. I actually read a lot of stuff I could find online ... reading product documentation would help me a lot ... I had no other choice."

Just like Kofi, when Yaw was not working part-time (in this case for another entrepreneur in one of the tech hubs), he was tinkering about in one of the hubs or online learning new skills to be "future-ready." He argued that "tech is actually the way out for Ghana." He said, "We've tried a lot of things, maybe into politics and such, but what is actually effecting the change is tech entrepreneurship."

"Tech is actually the way out for Ghana. We've tried a lot of things, maybe into politics and such, but what is actually effecting the change is tech entrepreneurship." 
In essence, Yaw, like many of those we met in Accra, saw working in tech as a way out and forward, from poverty to an economically prosperous state both for himself and for his country. The stakes were high enough that at one point when he had dropped out of school and was "hanging with the wrong crowd," even the guys there told him to go back to school and use his knack for technical things to improve his life and that of his family, which had fallen on hard times.

Besides enrolling in classes at hubs, watching YouTube videos, and reading product manuals, other participants mentioned browsing open courseware from American and European universities. This digital self-learning was one of the most common kinds of up-skilling work that many of the entrepreneurs in Accra put in after their other jobs. In some cases, participants asked the research team for help to access material online or, in one case, to help pay for an online course in U.S. dollars in exchange for the equivalent in Ghanaian cedis given barriers to international online payments. These examples highlight a common trend that the most disadvantaged populations often have to pay an additional cost (via money, time, or effort) to catch up to baseline skills and resources available to and taken for granted by more affluent groups.

\subsection{Technology Awareness and Maintenance}

While higher-income populations might be more comfortable with new tech devices because they can afford to keep up with their updates, those in low-resource communities put in additional effort to become aware of relevant online platforms (e.g., Instagram) and learn how to use them for work. These efforts were further hindered by having to purchase, repair, and maintain the physical technology (e.g., tablet) that provides access.

[D] Many neighborhoods in Detroit remain under-connected, and the city's digital divide is reported to be one of the most extreme in the USA [38]. For instance, business development organizations often make Facebook the primary source of information for livestreamed events, often with the assumption that it is the easiest way for people to maintain awareness. However, like Lana in the previous section, several lower-income participants did not use them, or faced challenges using them to their full extent. Participants also faced barriers to participating online because of seemingly simple challenges like forgetting their login password, not having a working microphone, having spotty Internet access, or not having broadband at home.

But, if they had the time and access to transportation, participants took the initiative to seek additional help to overcome technology challenges and participate. Other participants spent their Saturdays or weekday evenings at open business workshops, where they would seek advice on how to get their laptops set up with WiFi, fix general bugs (i.e. memory, audio), or learn how to use Facebook pages. This additional work of learning about technology often slowed down their business development process, or relegated them to offline forms of publicity, like flyers, in the meantime. These low-tech approaches to publicity, however, were limited and less likely to bring in higher-paying customers from outside their network.

[A] The technologies most visible with entrepreneurs in the Accra study were affordable smartphones from Chinese and Taiwanese companies such as Tecno, Huawei, Infinix, and HTC. The phones ranged in quality and sophistication, but in general, most of the entrepreneurs could afford a phone with internet capabilities. Many of these phones gave users the ability to monitor their data use and cut off where they were nearing a limit, a feature most used in conjunction with other measures from the telecom providers such as data bundling, as is common in that part of the world [14]. Most of the entrepreneurs, given that they were largely youthful, tended to be quite adept with these devices, particularly when it came to accessing information online. They picked these skills up either by observing other youth or by trial-and-error and social media. When the devices broke down, they were likely to find a repairer in the same market where they bought the phone. Increasingly, some of the Chinese brands provide in-house repair and warranty service.

Proc. ACM Hum.-Comput. Interact., Vol. 3, No. CSCW, Article 218. Publication date: November 2019. 
On the other hand, we observed that most laptops used for much more intense work such as learning to code were older IBM, Dell, or other PC models. For instance, in a coding class of 23 students at one of the hubs, 11 students had laptops, all of which were PCs several generations old. The only people with newer laptops were the teacher and the researchers. The other half of the class wrote down the code in notebooks they had brought along and shared the screens of those with laptops. Smart books, in part due to their affordability, such as Acer, were also common. As intimated by Kweku in his narration of his daily movements, the older laptops tended to be heavy and large and often broke down. When that happened, time and money had to be spent to repair them, but unlike phone repair, laptop repair was not as easily or cheaply available and took longer compared to phone repair.

\subsection{Overcoming Exclusion}

To access resources and signal one's position as an entrepreneur, many entrepreneurs joined hubs, like co-working spaces and accelerator programs, and frequented local organizations that supported business development. These spaces served as connectors between our study participants, local higher-income entrepreneurs, and the global digital economy. Yet, being in Accra or Detroit still meant being left out of broader discourses of cutting-edge innovation or economic development. These exclusions were acutely felt because they resulted in abrasive interactions with people of different classes, races, expertise, or privilege. To overcome them while at the same time acquiring skills necessary for socio-economic mobility, Accra and Detroit's low-income entrepreneurs needed to actively perform discursive and cultural work.

4.3.1 Navigating Cultural and Class Boundaries. In both contexts, cultural boundaries played a significant role in determining access to learning and resource-based opportunities. While these barriers were not physical, as described through the previous example of transportation, they were just as crucial in preventing participants from experiencing the full range of benefits their city offered.

[D] In one particularly memorable interview in Detroit, we asked an entrepreneur in a higherincome area whether other local entrepreneurs had reached out to him for advice online. He responded that he had received help requests, but:

"If they are not written well, I don't respond .... I know it sounds horrible, but it is totally language-based. The words that they use, and just the way that they come off. I mean I don't know if they are aware that they come off this way."

He expressed that he does not find it worthwhile to provide advice to someone with limited "professional" communication skills and that people from lower-income areas were less likely to be on time or have the appropriate mannerisms with customers.

On the opposing side, we observed how low-resource entrepreneurs faced significant challenges organizing their business plans and documenting them in writing, which are crucial to access funding. The hurdle of having to communicate using professional language would often stall their planning process for weeks or even months. As described, these class signifiers, such as language and tone, seeped into who the higher-income entrepreneurs decided to advise online. This highlights how simply being able to connect digitally is often not enough to foster productive relationships offline. Often those seeking help do not intend to come off as impolite but simply lack the communication skills needed to match those of the respondent, in part because of differences in education and social capital. Moreover, some modes of speaking are associated with certain races or social classes, and yet these are not always immediately recognized as such $[11,59]$. These cultural or class-based differences around communication, often mediated by technology, posed obstacles to our participants in connecting with people in more privileged networks. 
Another place where racial and class boundaries created friction was in regard to which enterprises attracted money from funders. The perception of the largely African-American entrepreneurs who lived further from the city-center was that those who could afford to now live in the gentrified parts of Detroit could more easily draw in investors. Such businesses, they felt, were more respected within the entrepreneurial network than the types of businesses they took on in less resourced areas. Whereas many saw their business as a necessity to make a living and support others in their community, the businesses downtown were geared toward Silicon Valley trends that relied on different growth models and thereby attracted different kinds of capital.

[A] In Accra, this type of Silicon Valley entrepreneurship was favored as a means to self-upgrade by the younger middle-class Accra dwellers. These were typically university-educated individuals who either did not find employment in their chosen field or were mismatched (under- or overemployed) for specific jobs. Nene, for instance, complained about how most of his engineering classmates ended up doing jobs where "you are not really doing engineering." Instead of being employed in that kind of role, he tried to build a consulting gig in which he provided engineering support to university students and companies. This eventually turned into a hardware startup that he is now the CEO of. Almost all the participants performing this kind of entrepreneurship focused on app development, IoT devices, digital games, and the like.

Some of these university-trained computer scientists and engineers felt they were equally as skilled as Silicon Valley entrepreneurs but felt sidelined in the global tech ecosystem, particularly in terms of access to funding. Whereas the Detroit entrepreneurs in the low-income areas felt sidelined relative to those in the gentrified city center, the exclusion these middle-class Accra entrepreneurs pertained to being African and living in Africa. These participants often mentioned the effect that the exclusion had in terms of their ability to build products that could scale and compete on the international market. For others, the exclusion was much more localized, in their being youthful and being dismissed by older Ghanaians who had the financial wherewithal to support them as being fanciful or not serious. To overcome these barriers, Accra tech entrepreneurs routinely sought events with high international visibility such as innovation challenges and hackathons organized by the World Bank, the British Council, and The Standard Chartered Bank, for example, to help them attract funding.

Another class of entrepreneurs experienced exclusions that required careful cultural navigation. This class included those without university education who also felt the pressure to add digital skills and technologies to their everyday hustle to become even more entrepreneurial. Some of these individuals made it to the hubs and recounted how they initially felt they did not belong in such spaces. Others who explicitly mentioned exclusions in the tech scene included younger (high school level) individuals who hung outside hubs but did not enter because they perceived or were explicitly told they were not welcome, even though the gates were open and the hubs operated under an open-door policy. Although the co-founder of one of the hubs insisted that all were welcome, the front desk staff had been telling the students he thought the boss would disapprove if he let them in to use the WiFi. This kind of exclusion reflects the complexity of Accra's neighborhoods and how class divides exist in the very same spaces as socio-economic diversity. This particular hub was housed in a building originally meant to be a luxury home but later converted into office spaces, and was next to smaller houses and shacks. The students often pretended to be chatting or playing while surreptitiously logging into the hub's open WiFi network. To become digitally connected, these young Accra dwellers hacked the social infrastructure around them.

4.3.2 Taking Control Over Narratives. Even though our participants often emphasized "necessitybased" entrepreneurship, motivated in part to guard against income instability, they also saw their 
work as an opportunity to reduce the socio-cultural divide in their community. They believed the external narratives about their city fed into the kinds of opportunities that came their way, and hoped their entrepreneurial efforts could change the way outsiders viewed their communities.

[D] In Detroit, the desire to benefit those around them from similar low-income backgrounds shaped what businesses participants chose to start and where. For instance, to bring awareness to the divergent experiences of low-income entrepreneurs, one participant, Robert, educated people through local tours on the history of African-American entrepreneurship in Detroit. He described quitting his job as a full-time teacher to share stories of local African-American history as often as he could:

"I gave up on the full-time teaching position and went ahead and took a chance at my business, although I continued to substitute teach, which means I get a call in the morning to ask, 'Do you want to take this assignment?' And I can say yes or no. So if I have bookings for tours, then I just say no...But if I don't have any bookings then I can say yes and I can go into work."

Robert took the risk to pursue his tour businesses because he felt that it had a larger impact on the education of the community. Since starting his business, he has become known as the "go-to" history tour leader in Detroit for students on field trips, parents interested in history, and out-of-town visitors.

Another participant, Angela, expressed similar pro-social motivations when she decided to open a grocery store that sells healthy food in her neighborhood. She described going through a longer process of hiring staff from the neighborhood, even though this required a more extensive vetting process and training. Even though these entrepreneurs could have made business decisions that were more profitable (e.g., locating the store in a more affluent area or employing people from outside the community), they chose to target their efforts to support those around them. In many cases, using social media helped spread the word about their business goals and assert their legitimacy as an entrepreneur both within and outside their community.

[A] In response to the perception that African enterprises were excluded from global technology and financial markets, some of the more visible entrepreneurs became evangelists for Accra, emphasizing the city's growing tech scene as an indicator of progress. Speaking at international events and through their digital engagements (e.g., blogs, podcasts), these entrepreneurs used their platform to draw interest and investment into their city. Another way that these entrepreneurs attempted to build a positive narrative, and shift from what they described as the global perception of Africa as a technological backwater, was to organize events or encourage international events such as re:publica, a German digital cultural festival, to be hosted in Accra. This additional discursive work was seen as necessary to keep the tech entrepreneurial scene going.

\section{DISCUSSION}

While Accra and Detroit differ in a number of ways with respect to geography, racial demographics, and culture, we found that entrepreneurs in both contexts face similar expectations and challenges around entrepreneurship and technology use. Despite Accra's ethnic diversity, one might argue that it is racially homogeneous, whereas Detroit's segregated areas, in many ways, represent the United States' multiracial population. Yet, these two cities, as well as many others around the world, are experiencing rising inequality born from a mix of neoliberal governance, economic instability, and histories of exploitation and neglect of the most vulnerable $[55,75,79,86]$. Economic precariousness and exploitation continue to be defining characteristics of the so-called global new economy $[44,98,101]$. 
From the various challenges and workarounds that entrepreneurs in Accra and Detroit do to self-entrepreneurialize, we observed a range of efforts that reflect prior work on labor. However, one important contribution that this paper makes is locating the pressure that people living in lowresource areas feel at the intersection of two powerful discourses about changing work practices in the new economy: entrepreneurialism and digital technology skills. Some participants who were already entrepreneurs were actively acquiring digital tech skills in an effort to enhance their ability to earn a living and be upwardly mobile. Others, who had already started acquiring technical skills, now felt an urgent need to learn how to be become better entrepreneurs. Together then, participants felt a strong impetus for combining the acquisition of various skills - social media promotion, coding, making, etc. - with the task of learning to become an entrepreneur, while juggling multiple gigs or hustles on the side. In low-income contexts, this presents additional pressures when it is already tough to make ends meet.

Moreover, doing all this while Black, either as an African within an international sphere of tech entrepreneurship, or African-American within a national sphere, turned out to be an important factor for how participants made sense of the exclusions they felt. That race remains salient across the world is clear, and the experiences of the Africans and the African diaspora, or what Paul Gilroy has described as "the Black Atlantic" [47], continues to be marked by their bodies and histories of colonization and oppression. Yet, as we saw in the ways that exclusion manifested in both Accra and Detroit, race often intersected with issues around class, particularly in terms of who was doing what kind of entrepreneurship, and what kinds of aspirations they articulated in their self-upgrade The pursuit of class mobility and racial uplift worked in tandem even as they showed frictions and fissures within the overly universalized discourse of entrepreneurialism and technology uptake. Rather than take the additional labors that participants undertook as unproblematic and inevitable shifts toward a techno entrepreneurial future, we show they live and are rendered as "marked subjects" in a racialized and classed world [9].

\subsection{Implications for Labor in the New Economy}

Entrepreneurs in low-income contexts are a unique worker population to study because they undertake multiple forms of labor in the new economy while experiencing hardships unique to their socio-economic status. As we highlighted in the prior work section, studies of the new economy show that, increasingly, entrepreneurship is becoming the de-facto option to achieve economic stability. It provides self-directed options to supplement part-time or full-time employment that is precarious or not enough to regularly pay the bills. People in these situations might hold traditional jobs in service work, performing invisible and emotional labor, but, at the same time, in pursuing their entrepreneurial efforts they take on additional risks and responsibilities beyond traditional employment, thus experiencing aspects of aspirational and venture labor. These combined labor experiences make the labor of entrepreneurs in resource-constrained communities particularly complex because they are performing this work both to meet survival needs and also to reach for something greater. The vagaries of maintaining the entrepreneurial self require moving in and out of various situations, picking up skills, technologies, and gigs, where possible, to survive and keep moving toward the goal of not just social mobility, but also community growth [61].

While the entrepreneurial self in these communities was, in some ways, closer to survival mode than the populations studied in venture, aspirational, and hope labor, the hopefulness and technooptimism attached to digital technologies manifested itself in similar ways. What was noticeably different, however, was how this hope was articulated in the communities we examined. In Accra, there was a lot of interest in solving everyday problems in Ghana and Africa that had already been solved in other parts of the world. Building a business or a technology that hacked the everyday was always entangled with the aspirations for personal development and upgrading. In Detroit, 
these goals were often businesses that would directly serve the city's resource-poor and shed light on systemic discrimination experienced in those communities. Self-upgrading turned into uplifting the community, and hopefulness meant a city that was better for those suffering the most.

Beyond the venture and aspirational labor, the additional physical labor we saw in Accra and Detroit was often draining and time-consuming. Even participating online required a lot of physical work navigating an unfriendly urban infrastructure. Logging on to the ever-present internet on a functioning laptop at home is qualitatively different from traveling to an internet cafe where electricity might not even be on. These experiences of our participants made online labor as physically draining as it was financially tasking. In other words, the "free labor" observed in the creative uncompensated work done online does not map neatly to what the low-income entrepreneurs in this paper were doing.

In our study contexts, all this entrepreneurial work had to be done while maintaining a livelihood, whether it was working a store for someone, teaching, or hairdressing, for example. How do we account for these differences and the work that low-income entrepreneurs take on to become the average worker described in previous labor scenarios [33]? In other words, how much work does it take to arrive at a similar stage to the creative bloggers and other valorized digital entrepreneurs, even if it was before they began blogging in the hopes of attracting professional and commercial attention? We do not suggest that the time taken to learn is of any less value among higherincome populations; rather, we emphasize that the costs to getting up to the same level, for one's entrepreneurial dreams to come true, are quite different. What we have detailed are the confluence of challenges that require additional resources and labor from already resource-strapped communities to keep up, upgrade, and innovate within the new economy. By showing some intersectional dimensions of this labor, we hope to open the space for collaboration with such communities in ways that are closer to their lived realities than what we, as researchers, imagine them to be.

In many ways, our findings about self-upgrading underscore the individual agency and proactive ways that individuals in low-resource areas work toward their daily livelihood, despite systemic "infrastructural inaccessibility" [19]. This is an important and necessary reminder, particularly given the still dominant discourse that low-resource populations look for handouts, whether it is through government assistance, or, in our case, design or research interventions by privileged academics.

\subsection{Supporting Entrepreneurs in Low-resource Urban Centers}

Informed by how residents of Accra and Detroit respond to the need to self-entrepreneurialize, we suggest that researchers and designers explore the following ways for reducing the burden of performing entrepreneurship in low-resource contexts: (1) orienting toward group-based support systems, (2) helping to sustain tech repair and maintenance ecologies, and (3) supporting opportunities for surviving and thriving.

5.2.1 Orienting Towards Group-based Local Support Systems. Our findings reveal a focus on performing entrepreneurship to support and work with the local community. Rather than emphasizing individualistic progress, we suggest respecting the inclination toward collective ways of working and building support. These motivations highlight opportunities to build on previous work on assets-based community development (ABCD) [77, 78], an approach from development literature emphasizing the importance of identifying local assets and then fostering relationships between them. For instance, this could involve identifying local change-makers, such as the community-motivated entrepreneurs featured in this study, and fostering collaborations and shared interests between them and local citizen associations if they are not connected already. Previous efforts using ABCD have typically focused on fostering collective activity toward a shared goal [20,40,52], whereas we suggest using these principles to foster social learning to achieve individual entrepreneurial goals 
(that eventually benefit the collective community). Situating these efforts within the community provides opportunities for locals to develop sources of knowledge and support, while reducing issues of exclusion related to long commutes and class/cultural barriers.

5.2.2 Sustaining Repair and Maintenance Ecologies. Technology maintenance and upkeep remains salient for low-income communities. As prior research on repair culture suggested [57, 65, 67, 68], there is a great need to address obsolescence and the up-skilling required for new digital tech users. The rapid introduction of new technology models combined with stricter warranty invalidation rules only widen the digital divide [56]. Participants in this study, as well as others around the world as detailed in the repair literature, often turn to repair as their only option.

In Accra, where everyone was using similar technology, it was easier to scale social support because one could more easily find someone who uses a similar model of phone or computer. Many of the tech solutions that came out of the hubs in Accra were built for the type of phones and computers the general Ghanaian population uses. In the coding class, waiting for a slow computer to catch up was not a severe impediment because everyone else was experiencing similar lags. In Detroit, however, using a lower-end device (e.g., built 15 years ago) put participants at a disadvantage compared to other technology users in the city, who were more likely to own recent models of Macs or PCs. In effect, this technological divide made it more difficult for entrepreneurs in the resource-constrained neighborhoods of Detroit to benefit from new forms of computer-based entrepreneurial support that were being offered to them.

Our contention is that if the goal of a technological intervention is to bridge communities and people across economic lines, we need to think more about the assumed underlying skills to see whether we might be projecting norms of our (relatively) privileged position as academics and industry professionals. We take the embedded skills underlying digital technology use, specifically for workforce and entrepreneurial training, for granted if we do not assess or support on-boarding populations that do not have the same kind of access or prior experience of use. This includes remembering that for both the urban poor in the Global North and much of the urban Global South, technology maintenance and repair is the reality [48, 57, 65, 67, 68]. The normalization of a "ubiquitously networked urbanism" - whether in the Global North or Global South - works to "deny the very possibility of spaces and times when networks are not available, or do not function" [pg. 11][49]. This creates situations in which the very people we as researchers are trying to help end up bearing additional burdens to fit into our normativity.

Instead, we advocate for breaking the practice of replacing, rather than repairing, that traps those from low-resource communities into old devices when they cannot afford new products. In Detroit, we saw initial efforts to build repair communities at local organizations. But, these events typically fostered relationships between volunteer "experts" (who typically own the latest devices) and technology "novices" (who typically own devices 10-20 years old), surfacing challenges of reconciling different mental models of how technology works. Combined with the class boundaries already in place in such places, such efforts took longer to provide needed support for the entrepreneurs coming from low-resource communities.

We suggest these communities learn from other regions where technology repair among peers is thriving, such as in Accra, Dhaka, or Kampala [56, 57, 68]. In particular, we see possibilities in taking more activist roles in advocating for the dismantling of repair regimes that lock out a significant part of the world's population. This might happen through privileged researchers in positions of power being advocates, or being more active in sociopolitical movements such as the right to repair, to support a large-scale shift toward greater accessibility for low-income populations. Another area we see possibility is in fostering the sharing of skills that can support old PC or phone repair as well or sharing knowledge on lower-price PCs that do not sacrifice power. For cities like Accra, 
where there is already a thriving mobile phone repair scene, we suggest supporting the knowledge transfer to PC repair as well, given the computer skill self-upgrading efforts taking place.

5.2.3 Supporting Opportunities for Surviving and Thriving. Many of the entrepreneurship ideas we encountered in these contexts were very keenly tuned to addressing the challenges of the community. While the aspect of surviving has been extensively studied in entrepreneurial work within ICTD literature [34-36, 42, 93], we also emphasize accounting for the more hopeful aspirations of performing entrepreneurship typically delegated to higher-income populations [39, 84]. In Detroit and Accra, this means aspiring toward a better life while regularly living the challenges of maintaining and upgrading skills and resources when there are limited avenues for support. Rather than taking an outsider approach and immediately designing to alleviate the most conspicuous issues, we suggest drawing on existing socially conscious intervention methods [16, 17, 30, 32, 41, 43, 88] to understand the range of goals among low-resource entrepreneurs and directly involve them in the process of identifying, researching, and building local interventions. Furthermore, the products of ideas we encountered in Accra and Detroit went beyond solving infrastructural problems allowing for "non-productive" activities and desires, the need to have fun, and the need for entertainment $[22,106]$. Wellness and having fun were just as important as helping to navigate a tough environment. This was part of the broader focus on community development that we saw in these cities. For instance, in Accra, a group of game developers emphasized the importance of their own pleasure and that of their users in the games they were building. This was as important as the functional need to optimize mobile platforms for slow internet connections. Actively seeking such values within the communities we engage with will lead to better systems of support in which low-income populations might become better positioned to thrive, not just survive.

\section{CONCLUSION}

Two interconnected discourses of entrepreneurialism and digital technology skills dominate visions of work in the new economy. This has created pressures to upgrade one's self as both an entrepreneur and a digital technology user and producer. In low-income urban centers such as Accra and Detroit, workers exhibit efforts to upgrading the self; a future-oriented outlook toward learning entrepreneurship and using related technologies for creating career opportunities, all while maintaining a precarious livelihood. At the same time, there is a continued need for technology maintenance while using (often) older generations of digital technologies that low-resource workers tend to have [48]. The cost of constantly upgrading to new technologies is too high relative to income and so entrepreneurs in both cities often sought help to repair devices or to learn to use them with newer systems or programs. All the while, infrastructural challenges tied to specific socio-political issues of these cities necessitated applying additional labor toward overcoming exclusion. All of these raise the costs of self-entrepreneurializing to catch up, upgrade, and innovate with technological change in the new economy. To support such efforts is to pay attention to these additional labors and contribute opportunities for upskilling, maintaining a living, and working toward expressed aspirations.

\section{ACKNOWLEDGMENTS}

We would like to thank the participants for sharing their experiences with us, and the entrepreneurial organizations for allowing us to observe their events. This work was supported by the NSF awards 1617898 and 1665049.

\section{REFERENCES}

[1] [n. d.]. Biz Grid. http://detroitbizgrid.com/. Accessed: 2018-04-18. 
[2] [n. d.]. Ghana Is the Star in IMFâĂŹs 2019 Economic Growth Forecast. https://www.bloomberg.com/news/articles/ 2019-04-10/ghana-is-the-star-in-imf-s-2019-economic-growth-forecast-chart/. Accessed: 2019-6-28.

[3] [n. d.]. Ghana Tech and Biz Hubs Network. http://tech-businesshubsgh.org. Accessed: 2019-06-25.

[4] [n. d.]. World Population Review. http://worldpopulationreview.com/us-cities/detroit-population/. Accessed: 2018-04-18

[5] 2014. Ghana Living Standards Survey Round 6 (GLSS6). Ghana Statisical Service. Accra (2014).

[6] Crystal Abidin. 2016. Visibility labour: Engaging with InfluencersâĂŹ fashion brands and\# OOTD advertorial campaigns on Instagram. Media International Australia 161, 1 (2016), 86-100.

[7] Susan Ager. 2015. Tough, cheap, and real, Detroit is cool again. National Geographic (2015).

[8] Paula Allen-Meares. 2017. A Twenty-first Century Approach to Community Change: Partnering to Improve Life Outcomes for Youth and Families in Under-served Neighborhoods. Oxford University Press.

[9] Sareeta Amrute. 2016. Encoding race, encoding class: Indian IT workers in Berlin. Duke University Press.

[10] Daniel Ashton. 2011. Upgrading the self: Technology and the self in the digital games perpetual innovation economy. Convergence 17, 3 (2011), 307-321.

[11] Peter Auer. 2013. Code-switching in conversation: Language, interaction and identity. Routledge.

[12] Seyram Avle and Silvia Lindtner. 2016. Design (ing)'Here'and'There': Tech Entrepreneurs, Global Markets, and Reflexivity in Design Processes. In Proceedings of the 2016 CHI Conference on Human Factors in Computing Systems. ACM, 2233-2245.

[13] Seyram Avle, Silvia Lindtner, and Kaiton Williams. 2017. How methods make designers. In Proceedings of the 2017 CHI Conference on Human Factors in Computing Systems. ACM, 472-483.

[14] Seyram Avle, Emmanuel Quartey, and David Hutchful. 2018. Research on Mobile Phone Data in the Global South: Opportunities and Challenges. The Oxford Handbook of Networked Communication (2018).

[15] Anna Bahney. 2017. More than 44 million Americans have a side hustle. CNN Money 12 (2017).

[16] Jeffrey Bardzell and Shaowen Bardzell. 2013. What is critical about critical design?. In Proceedings of the SIGCHI conference on human factors in computing systems. ACM, 3297-3306.

[17] Shaowen Bardzell. 2010. Feminist HCI: taking stock and outlining an agenda for design. In Proceedings of the SIGCHI conference on human factors in computing systems. ACM, 1301-1310.

[18] Mark Binelli. 2013. Detroit city is the place to be: The afterlife of an American metropolis. Macmillan.

[19] Pernille Bjørn and Nina Boulus-Rødje. 2018. Infrastructural inaccessibility: Tech entrepreneurs in occupied palestine. ACM Transactions on Computer-Human Interaction (TOCHI) 25, 5 (2018), 26.

[20] Tony Bovaird. 2007. Beyond engagement and participation: User and community coproduction of public services. Public administration review 67, 5 (2007), 846-860.

[21] Anita Say Chan. 2013. Networking peripheries: Technological futures and the myth of digital universalism. MIT Press.

[22] Padma Chirumamilla and Joyojeet Pal. 2013. Play and power: a ludic design proposal for ICTD. In Proceedings of the Sixth International Conference on Information and Communication Technologies and Development: Full Papers-Volume 1. ACM, 25-33.

[23] Nicole S Cohen. 2015. Cultural work as a site of struggle: Freelancers and exploitation. Marx and the Political Economy of the Media (2015), 36-64.

[24] Jean Comaroff and John L Comaroff. 2015. Theory from the South: Or, how Euro-America is evolving toward Africa. Routledge.

[25] Jennifer Conlin. 2011. Detroit pushes back with young muscles. New York Times (2011).

[26] Gerald F Davis. 2016. The vanishing American corporation: Navigating the hazards of a new economy. BerrettKoehler Publishers.

[27] Tawanna R Dillahunt. 2014. Fostering social capital in economically distressed communities. In Proceedings of the SIGCHI Conference on Human Factors in Computing Systems. ACM, 531-540.

[28] Tawanna R. Dillahunt, Nishan Bose, Suleman Diwan, and Asha Chen-Phang. 2016. Designing for Disadvantaged Job Seekers: Insights from Early Investigations. In Proceedings of the 2016 ACM Conference on Designing Interactive Systems (DIS '16). ACM, New York, NY, USA, 905-910.

[29] Tawanna R Dillahunt and Amelia R Malone. 2015. The promise of the sharing economy among disadvantaged communities. In Proceedings of the 33rd Annual ACM Conference on Human Factors in Computing Systems. ACM 2285-2294.

[30] Carl DiSalvo. 2012. Adversarial design. The MIT Press.

[31] Lynn Dombrowski, Adriana Alvarado Garcia, and Jessica Despard. 2017. Low-wage precarious workers' sociotechnical practices working towards addressing wage theft. In Proceedings of the $2017 \mathrm{CHI}$ Conference on Human Factors in Computing Systems. ACM, 4585-4598.

Proc. ACM Hum.-Comput. Interact., Vol. 3, No. CSCW, Article 218. Publication date: November 2019. 
[32] Lynn Dombrowski, Ellie Harmon, and Sarah Fox. 2016. Social Justice-Oriented Interaction Design: Outlining Key Design Strategies and Commitments. In Proceedings of the 2016 ACM Conference on Designing Interactive Systems (DIS '16). ACM, New York, NY, USA, 656-671.

[33] Brooke Erin Duffy. 2017. (Not) getting paid to do what you love: Gender, social media, and aspirational work. Yale University Press.

[34] Richard Duncombe. 2006. Using the livelihoods framework to analyze ICT applications for poverty reduction through microenterprise. Information Technologies \& International Development 3, 3 (2006), pp-81.

[35] Richard Duncombe and Richard Heeks. 2002. Enterprise across the digital divide: information systems and rural microenterprise in Botswana. Journal of International Development 14, 1 (2002), 61-74.

[36] Richard Duncombe and Alemayehu Molla. 2009. Formalisation of information systems in developing country small and medium enterprises. African Journal of Information Systems 1, 2 (2009), 1-29.

[37] Kathleen M Eisenhardt and Melissa E Graebner. 2007. Theory building from cases: Opportunities and challenges. Academy of management journal 50, 1 (2007), 25-32.

[38] Laleah Fernandez, Bianca C Reisdorf, and William H Dutton. 2019. Urban Internet myths and Realities: A Detroit case study. Information, Communication \& Society (2019), 1-22.

[39] Richard Florida. 2014. The rise of the creative class-revisited: Revised and expanded. Basic Books (AZ).

[40] Jane Foot and Trevor Hopkins. 2010. A glass half-full: how an asset approach can improve community health and well-being. Great Britain improvement and development agency.

[41] Andrea Forte, Nazanin Andalibi, Thomas Park, and Heather Willever-Farr. 2014. Designing information savvy societies: an introduction to assessability. In Proceedings of the SIGCHI Conference on Human Factors in Computing Systems. ACM, 2471-2480.

[42] Christopher Foster and Richard Heeks. 2010. Researching ICT Micro-Enterprise in Developing Countries: Themes, Wider Concepts and Future Directions. The Electronic Journal of Information Systems in Developing Countries 43, 1 (2010), 1-20.

[43] Batya Friedman and David G. Hendry. 2004. Value sensitive design. (2004).

[44] Christian Fuchs and Sebastian Sevignani. 2013. What Is Digital Labour? What Is Digital Work? WhatâĂŹs Their Difference? And Why Do These Questions Matter for Understanding Social Media? tripleC: Communication, Capitalism \& Critique 11 (2): 237-293.

[45] Elizabeth M Gerber, Julie S Hui, and Pei-Yi Kuo. 2012. Crowdfunding: Why people are motivated to post and fund projects on crowdfunding platforms. In Proceedings of the International Workshop on Design, Influence, and Social Technologies: Techniques, Impacts and Ethics, Vol. 2. ACM New York, NY.

[46] Tarleton Gillespie. 2014. The relevance of algorithms. Media technologies: Essays on communication, materiality, and society 167 (2014), 167.

[47] Paul Gilroy. 1993. The black Atlantic: Modernity and double consciousness. Verso.

[48] Amy Gonzales. 2017. Technology Maintenance: A New Frame for Studying Poverty and Marginalization. In Proceedings of the 2017 CHI Conference on Human Factors in Computing Systems. ACM, 289-294.

[49] Stephen Graham and Nigel Thrift. 2007. Out of order: Understanding repair and maintenance. Theory, Culture \& Society 24, 3 (2007), 1-25.

[50] Mary L Gray and Siddharth Suri. 2019. Ghost Work: How to Stop Silicon Valley from Building a New Global Underclass. Eamon Dolan Books.

[51] Mary L Gray, Siddharth Suri, Syed Shoaib Ali, and Deepti Kulkarni. 2016. The crowd is a collaborative network. In Proceedings of the 19th ACM conference on computer-supported cooperative work \& social computing. ACM, 134-147.

[52] Gary Paul Green and Anna Haines. 2015. Asset building \& community development. Sage publications.

[53] Anikó Hannák, Claudia Wagner, David Garcia, Alan Mislove, Markus Strohmaier, and Christo Wilson. 2017. Bias in online freelance marketplaces: Evidence from taskrabbit and fiverr. In Proceedings of the 2017 ACM Conference on Computer Supported Cooperative Work and Social Computing. ACM, 1914-1933.

[54] Jean Hardy and Silvia Lindtner. 2017. Constructing a desiring user: Discourse, rurality, and design in location-based social networks. In Proceedings of the 2017 ACM Conference on Computer Supported Cooperative Work and Social Computing. ACM, 13-25.

[55] David Harvey. 2007. A brief history of neoliberalism. Oxford University Press, USA.

[56] Lara Houston and Steven J Jackson. 2016. Caring for the next billion mobile handsets: opening proprietary closures through the work of repair. In Proceedings of the Eighth International Conference on Information and Communication Technologies and Development. ACM, 10.

[57] Lara Houston, Steven J Jackson, Daniela K Rosner, Syed Ishtiaque Ahmed, Meg Young, and Laewoo Kang. 2016. Values in repair. In Proceedings of the $2016 \mathrm{CHI}$ conference on human factors in computing systems. ACM, 1403-1414. 
[58] Julie S Hui, Elizabeth M Gerber, and Darren Gergle. 2014. Understanding and leveraging social networks for crowdfunding: opportunities and challenges. In Proceedings of the 2014 conference on Designing interactive systems. ACM, 677-680.

[59] Julie S Hui, Darren Gergle, and Elizabeth M Gerber. 2018. IntroAssist: A Tool to Support Writing Introductory Help Requests. In Proceedings of the 2018 CHI Conference on Human Factors in Computing Systems. ACM, 22.

[60] Julie S Hui, Michael D Greenberg, and Elizabeth M Gerber. 2014. Understanding the role of community in crowdfunding work. In Proceedings of the 17th ACM conference on Computer supported cooperative work \& social computing. ACM, 62-74.

[61] Julie S Hui, Kentaro Toyama, Joyojeet Pal, and Tawanna Dillahunt. 2018. Making a Living My Way: Necessity-driven Entrepreneurship in Resource-Constrained Communities. In Proceedings of the ACM Conference on Computer Supported Cooperative Work \& Social Computing. ACM.

[62] Lilly Irani. 2015. Hackathons and the making of entrepreneurial citizenship. Science, Technology, \& Human Values 40, 5 (2015), 799-824.

[63] Lilly Irani. 2019. Chasing Innovation: Making Entrepreneurial Citizens in Modern India. Princeton University Press.

[64] Lilly Irani, Janet Vertesi, Paul Dourish, Kavita Philip, and Rebecca E Grinter. 2010. Postcolonial computing: a lens on design and development. In Proceedings of the SIGCHI conference on human factors in computing systems. ACM, 1311-1320.

[65] Steven J Jackson. 2014. Rethinking Repair. Media technologies: Essays on communication, materiality, and society (2014), 221-39.

[66] Steven J Jackson, Tarleton Gillespie, and Sandy Payette. 2014. The policy knot: re-integrating policy, practice and design in cscw studies of social computing. In Proceedings of the 17th ACM conference on Computer supported cooperative work \& social computing. ACM, 588-602.

[67] Steven J Jackson and Laewoo Kang. 2014. Breakdown, obsolescence and reuse: HCI and the art of repair. In Proceedings of the SIGCHI Conference on Human Factors in Computing Systems. ACM, 449-458.

[68] Steven J Jackson, Alex Pompe, and Gabriel Krieshok. 2012. Repair worlds: maintenance, repair, and ICT for development in rural Namibia. In Proceedings of the ACM 2012 conference on Computer Supported Cooperative Work. ACM, 107116.

[69] Jon Kolko. 2014. Learning entrepreneurial hustle. interactions 21, 2 (2014), 26-27.

[70] Kathleen Kuehn and Thomas F Corrigan. 2013. Hope labor: The role of employment prospects in online social production. The Political Economy of Communication 1, 1 (2013).

[71] James H Lee. 2012. Hard at work in the jobless future. The futurist 46, 2 (2012), 32.

[72] Min Kyung Lee, Daniel Kusbit, Evan Metsky, and Laura Dabbish. 2015. Working with machines: The impact of algorithmic and data-driven management on human workers. In Proceedings of the 33rd Annual ACM Conference on Human Factors in Computing Systems. ACM, 1603-1612.

[73] Michael Liegl. 2014. Nomadicity and the care of placeâĂTon the aesthetic and affective organization of space in freelance creative work. Computer Supported Cooperative Work (CSCW) 23, 2 (2014), 163-183.

[74] Silvia Lindtner. 2017. laboratory of the precarious: prototyping entrepreneurial living in shenzhen. Women's Studies Quarterly 45, 3/4 (2017), 287-305.

[75] Silvia Lindtner and Seyram Avle. 2017. Tinkering with Governance: Technopolitics and the Economization of Citizenship. Proc. ACM Hum.-Comput. Interact 1 (2017).

[76] Silvia Lindtner, Garnet D Hertz, and Paul Dourish. 2014. Emerging sites of HCI innovation: hackerspaces, hardware startups \& incubators. In Proceedings of the SIGCHI Conference on Human Factors in Computing Systems. ACM, 439-448.

[77] Alison Mathie and Gord Cunningham. 2003. From clients to citizens: Asset-based community development as a strategy for community-driven development. Development in practice 13, 5 (2003), 474-486.

[78] John L McKnight, John Kretzmann, et al. 1996. Mapping community capacity. Institute for Policy Research, Northwestern University Evanston, IL.

[79] Angela McRobbie. 2002. Clubs to companies: Notes on the decline of political culture in speeded up creative worlds. Cultural studies 16, 4 (2002), 516-531.

[80] Naja L Holten Møller, Irina Shklovski, M Silberman, Lynn Dombrowski, and Airi Lampinen. 2017. A ConstructiveCritical Approach to the Changing Workplace and its Technologies. In Proceedings of 15th European Conference on Computer-Supported Cooperative Work-Panels, Posters and Demos. European Society for Socially Embedded Technologies (EUSSET).

[81] Ethan Mollick. 2014. The dynamics of crowdfunding: An exploratory study. Journal of business venturing 29, 1 (2014), 1-16.

[82] Vincent Mosco. 2005. The digital sublime: Myth, power, and cyberspace. Mit Press. 
[83] Grace Muthoni Mwaura. 2017. The side-hustle: diversified livelihoods of Kenyan educated young farmers. IDS Bulletin 48, 3 (2017).

[84] Gina Neff. 2012. Venture labor: Work and the burden of risk in innovative industries. MIT press.

[85] David Nemer, Ian Spangler, and Michaelanne Dye. 2018. Airbnb and the Costs of Emotional Labor in Havana, Cuba. In Companion of the 2018 ACM Conference on Computer Supported Cooperative Work and Social Computing. ACM, 245-248.

[86] Aihwa Ong. 2006. Neoliberalism as exception: Mutations in citizenship and sovereignty. Duke University Press.

[87] Aihwa Ong and Stephen Collier. 2005. Global assemblages. Technology, politics and (2005).

[88] Ilse Oosterlaken. 2009. Design for development: A capability approach. Design issues 25, 4 (2009), 91-102.

[89] Joyojeet Pal, Priyank Chandra, Terence O’neill, Maura Youngman, Jasmine Jones, Ji Hye Song, William Strayer, and Ludmila Ferrari. 2016. An accessibility infrastructure for the Global South. In Proceedings of the Eighth International Conference on Information and Communication Technologies and Development. ACM, 24.

[90] James A Parrott and Michael Reich. 2018. An Earnings Standard for New York CityâĂŹs App-based Drivers. (2018).

[91] Michael Peters. 2009. Education, enterprise culture and the entrepreneurial self: A Foucauldian perspective. The Journal of Educational Enquiry 2, 2 (2009).

[92] Annie Pilon. 2015. Detroit is Trying to Become the Next Major Tech Hub. https://smallbiztrends.com/2015/06/ techtown-detroit.html. Small Business trends (2015).

[93] Nimmi Rangaswamy and Sumitra Nair. 2010. The mobile phone store ecology in a Mumbai slum community: Hybrid networks for enterprise. Information technologies \& international development 6, 3 (2010), pp-51.

[94] Noopur Raval and Paul Dourish. 2016. Standing out from the crowd: Emotional labor, body labor, and temporal labor in ridesharing. In Proceedings of the 19th ACM Conference on Computer-Supported Cooperative Work \& Social Computing. ACM, 97-107.

[95] Laura A Reese, Jeanette Eckert, Gary Sands, and Igor Vojnovic. 2017. "It's safe to come, we've got lattes": Development disparities in Detroit. Cities 60 (2017), 367-377.

[96] Alex Rosenblat. 2018. Uberland: how algorithms are rewriting the rules of work. Univ of California Press.

[97] Kjeld Schmidt and Liam Bannon. 2013. Constructing CSCW: The first quarter century. Computer supported cooperative work (CSCW) 22, 4-6 (2013), 345-372.

[98] Trebor Scholz. 2012. Digital labor: The Internet as playground and factory. Routledge.

[99] Robert E Stake. 2005. Qualitative case studies. (2005).

[100] Thomas J Sugrue. 2014. The Origins of the Urban Crisis: Race and Inequality in Postwar Detroit-Updated Edition. Vol. 6. Princeton University Press.

[101] Tiziana Terranova. 2000. Free labor: Producing culture for the digital economy. Social text 18, 2 (2000), 33-58.

[102] Jacob Thebault-Spieker, Daniel Kluver, Maximilian A Klein, Aaron Halfaker, Brent Hecht, Loren Terveen, and Joseph A Konstan. 2017. Simulation Experiments on (the Absence of) Ratings Bias in Reputation Systems. Proceedings of the ACM on Human-Computer Interaction 1, CSCW (2017), 101.

[103] Jacob Thebault-Spieker, Loren Terveen, and Brent Hecht. 2017. Toward a geographic understanding of the sharing economy: Systemic biases in UberX and TaskRabbit. ACM Transactions on Computer-Human Interaction (TOCHI) 24, 3 (2017), 21.

[104] Tatiana Adeline Thieme. 2018. The hustle economy: Informality, uncertainty and the geographies of getting by. Progress in Human Geography 42, 4 (2018), 529-548.

[105] Julia Ticona. 2015. Strategies of control: workersâĂŹ use of ICTs to shape knowledge and service work. Information, Communication \& Society 18, 5 (2015), 509-523.

[106] Kentaro Toyama. 2018. From needs to aspirations in information technology for development. Information Technology for Development 24, 1 (2018), 15-36.

[107] Anna Lowenhaupt Tsing. 2011. Friction: An ethnography of global connection. Princeton University Press.

[108] Anna Lowenhaupt Tsing. 2015. The mushroom at the end of the world: On the possibility of life in capitalist ruins. Princeton University Press.

[109] Danielle Van Jaarsveld and Winifred R Poster. 2013. Call centers: Emotional labor over the phone. In Emotional Labor in the 21st Century. Routledge, 173-194.

[110] Earnest Wheeler and Tawanna R. Dillahunt. 2018. Navigating the Job Search as a Low-Resourced Job Seeker. In Proceedings of the SIGCHI Conference on Human Factors in Computing Systems (CHI '18). ACM, New York, NY, USA.

[111] Amanda Williams, Silvia Lindtner, Ken Anderson, and Paul Dourish. 2014. Multisited design: An analytical lens for Transnational HCI. Human-Computer Interaction 29, 1 (2014), 78-108.

[112] Richard Winter. 1996. Some principles and procedures for the conduct of action research. New directions in action research (1996), 9-22. 
[113] Susan P Wyche, Andrea Forte, and Sarita Yardi Schoenebeck. 2013. Hustling online: understanding consolidated facebook use in an informal settlement in Nairobi. In Proceedings of the SIGCHI conference on human factors in computing systems. ACM, 2823-2832.

[114] Robert K Yin. 2017. Case study research and applications: Design and methods. Sage publications.

Received April 2019; revised June 2019; accepted August 2019 